\title{
Design and manufacture of a high-temperature PEMFC and its cooling system to power a lightweight UAV for a high altitude mission
}

\author{
Jordi Renau ${ }^{1}$, Jorge Barroso ${ }^{2}$, Antonio Lozano ${ }^{2}$, Andres Nueno ${ }^{2}$, Fernando Sán- \\ chez ${ }^{1}$, Jesús Martín ${ }^{2}$, Félix Barreras ${ }^{2, *}$ \\ ${ }^{1}$ University CEU Cardenal Herrera. San Bartolomé, 55. 46115 Alfara del Patriarca, \\ Valencia, SPAIN \\ ${ }^{2}$ LIFTEC, CSIC - Univ. Zaragoza. María de Luna, 10. 50018, Zaragoza, SPAIN
}

\begin{abstract}
In the present study, the optimal design of a high-temperature proton exchange membrane fuel cell (HT-PEMFC) that will be used to power an unmanned aerial vehicle (UAV) in a high altitude mission is performed. The use of PEMFCs for service ceiling above $10 \mathrm{~km}$ implies overcoming a number of problems caused by the harsh environmental conditions. Among them, new strategies to manage the heat generated by electrochemical reactions are needed. The maximum power required by the UAV was determined solving the aerodynamic problem, and the design of the lightweight HTPEMFC, including its cooling system, was optimized. To perform the numerical solution of the heat transfer problem, a computational code was implemented using the EES software. The decisions adopted resulted in a 40-cells stack with an electric power above $1 \mathrm{~kW}$ and a weight around $3.65 \mathrm{~kg}$. Besides, it is demonstrated that, for the configuration considered in the study, a passive cooling system without any additional fan system can be used to maintain the stack temperature in $160^{\circ} \mathrm{C}$.
\end{abstract}

Keywords: PEM fuel cell; High-temperature; Hydrogen; UAV; Heat transfer management; Cooling system

* Corresponding author. E-Mail: felix@litec.csic.es 


\section{Nomenclature}

\section{Latin alphabet}

$A \quad$ area $\left(\mathrm{m}^{2}\right)$

Bi Biot number

$C_{p} \quad$ specific heat $\left(\mathrm{J} \mathrm{kg}^{-1} \mathrm{~K}^{-1}\right)$

$D_{e q} \quad$ equivalent diameter (m)

$F \quad$ heat transfer area $\left(\mathrm{m}^{2}\right)$

$H \quad$ air enthalpy $\left(\mathrm{J} \mathrm{kg}^{-1}\right)$

$h$ heat transfer coefficient

$\left(\mathrm{W} \mathrm{m} \mathrm{m}^{-2} \mathrm{~K}^{-1}\right)$

K minor losses coefficient

$L \quad$ length of the stack (m)

Lc characteristic length (m)

$\dot{m} \quad$ mass flow rate $\left(\mathrm{kg} \mathrm{s}^{-1}\right)$

$\mathrm{Nu} \quad$ Nusselt number

$\Delta p \quad$ pressure drop $(\mathrm{Pa})$

$P \quad$ perimeter $(\mathrm{m})$

Pr Prandtl number

$Q \quad$ heat flux (W)

Re Reynolds number

$T \quad$ temperature (K)

$V \quad$ velocity $\left(\mathrm{m} \mathrm{s}^{-1}\right)$

$\dot{W} \quad$ power consumption (W)

\section{Greek letters}

$\epsilon \quad$ emissivity

$\sigma \quad$ Stefan-Boltzmann constant

$\left(5.67 \times 10^{-8} \mathrm{~W} \mathrm{~m}^{-2} \mathrm{~K}^{-4}\right)$

$\lambda$ thermal conductivity

$\left(\mathrm{W} \mathrm{m}^{-1} \mathrm{~K}^{-1}\right)$

\section{Subscripts}

$a, i \quad$ air inlet

$a, o$ air outlet

air air

b body

cool cooling system

cond cooling duct

conv convection

dis dissipated heat

elect electric

$f$ flow

FC fuel cell

HT heat transfer

i gaseous species

$\log \quad$ logaritmic

rad radiation

valv inlet valves

$w \quad$ stack surface

wet wet 


\section{Introduction}

The worldwide increase in energy demand in recent years has been responded by a raise in the combustion of fossil fuels. As a consequence, natural reserves are diminishing at an alarming rate. Entailed problems of pollutant emissions, greenhouse effect and acid rain are also aggravated. This has led to an agreement of EU and G8 leaders to reach by 2050 a reduction of $80 \%$ in carbon dioxide emissions from the levels measured in 1990. It is expected that the atmospheric concentration of $\mathrm{CO}_{2}$ can be stabilized at 450 ppm, and the increase in global temperature will be below $2^{\circ} \mathrm{C}$ relative to its preindustrial level [1]. To achieve these goals, the transport sector, which is responsible to a large extent of $\mathrm{CO}_{2}$ emissions, would require a decarbonization up to 95\% [2]. However, in the aeronautic sector in particular, $\mathrm{CO}_{2}$ emissions are projected to grow in approximately $6 \%$ by 2050 , due to the increase in global travel demand [3]. Under this scenario, hopes are deposited in zero-emissions fuel cell electric vehicles (FCEV) as a clean alternative for both terrestrial and aerial transportation $[4,5]$.

For high altitude flights ( $>10 \mathrm{~km}$ ) of small unmanned aerial vehicles (UAVs) the low atmospheric pressure $(0.26 \mathrm{bar})$ and oxygen partial pressure $(0.05 \mathrm{bar})$ impose severe limitations to the operation of atmospheric reciprocating internal combustion engines (ICE) because the intake air charge to the engine is drastically diminished. Unfortunately, small UAVs usually powered by ICEs with small cylinder capacity cannot incorporate compressors or other alternative systems to increase the intake pressure. This would increase the total aircraft payload, which cannot be afforded in this type of platforms. The combination of electric motors with fuel cells can be an alternative because its efficiency is much better than that of a mini-ICE, for any rpm range. The use of proton exchange membrane fuel cells (PEMFCs) in power units of small UAVs has been reported in different demonstration projects during the last years [6,7], but test flights were limited to very low range at sea level. PEMFCs can be designed to operate at high altitudes, taking into account the special requirements for this application. For PEMFC-based powerplants, the above-commented harsh environmental conditions at a cruising altitude of $10 \mathrm{~km}$ force to carry on board compressed gas bottles not only for hydrogen but also for oxygen (or air) in order to perform anodic and cathodic electrochemical reactions. At this height, the standard atmospheric temperature is below $-50^{\circ} \mathrm{C}$, with very dry air humidity [8], which hinders the correct management of the produced heat. In the present research, a high-temperature PEMFC (HT-PEMFC) with an operating temperature around $160^{\circ} \mathrm{C}$ has been used. This technology has several advantages com- 
pared to low-temperature PEMFCs that work around $50^{\circ} \mathrm{C}$. From the efficiency point of view, the increase in the working temperature enhances the electrochemical reaction rates, especially at the cathode side. Besides, it also eases the extraction of the water produced at the cathode sides because it is managed in vapor phase. From the technological point of view, heavy, bulky and inaccurate humidification systems for the reactant gases can be avoided, and the cooling system can be simpler and compact due to the large difference between the stack working temperature and the surroundings. As a result, the powerplant mass-specific and volume-specific power densities are enhanced. This is very important for light UAV platforms due to the severe restrictions for both the total weight that can be carried on board and the space available.

The objective of this research is to perform the optimal design, manufacture and operational tests of a lightweight HT-PEMFC that will be used to power an existing UAV for a high altitude mission. Simultaneously, the suitable cooling system needed to maintain the stack temperature in the recommended value $\left(160^{\circ} \mathrm{C}\right)$ during the whole flight is also designed. To this end, a computational code was implemented, which enables the iterative solution of the mass and energy conservation equations, together with the equations of heat transfer and pressure losses.

\section{Design of the HT-PEMFC stack}

In order to estimate the power needed to reach a service ceiling of $10 \mathrm{~km}$, the aerodynamic problem for the given aircraft has to be solved for a given ascending strategy. The UAV considered for this research was manufactured by the company Mediterranean of Aviation (Medavia, Ltd.), and has a total airframe mass of $3 \mathrm{~kg}$, a wing surface area of 0.8 $\mathrm{m}^{2}$, a wingspan of $4 \mathrm{~m}$, and a total length of $1.6 \mathrm{~m}$. In a previous study it was calculated that when the ascension of this UAV is performed with constant power supplied to the propeller, the rate of climb (RC) decreases with height, the climbing time is minimized, and the total required energy is also minimum [9]. So, the results obtained with the parametric analysis showed that the power demanded by the propeller is $422 \mathrm{~W}$, with a rate of climb at service ceiling $(10 \mathrm{~km})$ of $0.9 \mathrm{~m} / \mathrm{s}$. However, to properly estimate the actual power that has to be yielded by the stack, the efficiency of the different elements of the powertrain (DC/DC converter, electric motor, transmission and propeller) has to be considered. In this case, the total efficiency for the powertrain is $68.4 \%$, and the resulting power that must be delivered by the stack is around $650 \mathrm{~W}$ (maximum). 
To start the design of the stack some decisions have to be taken. In this case, it was decided to use the commercial membrane electrode assembly (MEAs) Celtec ${ }^{\circledR}$-P 1100 supplied by BASF Fuel Cells, with a standard rectangular active area of $81.28 \mathrm{~cm}^{2}$. Celtec-P high-temperature membrane consists in a polibenzimidazole (PBI) immobile gel phase doped with concentrated phosphoric acid (PA). For optimal doping methods and PA concentration, this membrane ensures an acceptable proton conductivity and gas permeability [10-12]. The operating temperature ranges from $120^{\circ} \mathrm{C}$ to $180^{\circ} \mathrm{C}$, and no humidification for reactant gases is needed. Following the recommendations of the MEAs' manufacturer to enlarge the lifetime of the stack, it must work in a stationary regime with a current density below $0.5 \mathrm{~A} \mathrm{~cm}^{-2}$. So, according to the polarization curve experimentally obtained in our lab for one of these MEAs, it has been decided that the current density of the HT-PEMFC stack will be of $0.45 \mathrm{~A} \mathrm{~cm}^{-2}$, which yields a total current of $36.58 \mathrm{~A}$. For this operating point, the voltage per cell is $0.45 \mathrm{~V}$ and then, the resulting working stack power is $658 \mathrm{~W}$ if 40 cells are stacked.

\subsection{Monopolar plates and flowfield geometries}

The dimensions of the flowfield geometry, and by extension those of the bipolar plates, are mainly influenced by the size of the MEAs. Even when the operational characteristics of HT-PEMFCs allow the use of very simple flowfield geometries, a careful design of this element has been performed. To tackle the design of the flowfield geometry, the consumption of reactant gases has to be known. For the given stack power and considering a flow stoichiometry of 1.2 for hydrogen, and 2 for oxygen, the expected consumptions are $13.5 \mathrm{Nl} / \mathrm{min}$ and $12.3 \mathrm{Nl} / \mathrm{min}$, respectively.

The optimal design of the channel size includes the estimation of both pressure and velocity fields, in order to ensure the homogeneous distribution of reactant gases over the catalyst layers [13-16]. Using a design procedure based on Navier-Stokes equations for mass and momentum conservation, an initial channel diameter is assumed and both gas flow velocity and Reynolds number are calculated, ensuring a laminar flow inside the channels. For the present plates, a serpentine-parallel geometry has been selected to cover the whole flowfield area in both anode and cathode plates. It is formed by 3 blocks of 10 channels with a total length of $392.4 \mathrm{~mm}$, as depicted in Fig. 1. The channels of the anode plates have a rectangular cross section $1 \mathrm{~mm}$ width and $0.5 \mathrm{~mm}$ depth, spaced by ribs $1 \mathrm{~mm}$ thick, introducing a total pressure drop of $24.1 \mathrm{~Pa}$. Similarly, channels at the cathode plates have a squared cross section of $1 \mathrm{x} 1 \mathrm{~mm}^{2}$, resulting in a total pressure 
drop of $60.5 \mathrm{~Pa}$. Considering that the 3 blocks of serpentine channels are spaced by ribs $1.95 \mathrm{~mm}$ thick, and that the number of ribs spacing the channels in every block is 9 (27 in total), $1.3 \mathrm{~mm}$ thick, $48.3 \%$ of the MEA active area $\left(39.25 \mathrm{~cm}^{2}\right)$ is directly exposed to the reactant gases flow, while the remaining area $\left(42.03 \mathrm{~cm}^{2}\right.$, representing $51.7 \%$ of the total surface) corresponds to the ribs ensuring the suitable electrical contact between plates and GDLs. Finally, in order to ensure that the MEAs are subjected to an appropriate compression rate, a receding housing of $0.2 \mathrm{~mm}$ was manufactured for the area where the MEAs are positioned. So, the maximum compression rate is $80 \%$ as recommended by the manufacturer, simultaneously guaranteeing a good electrical contact.

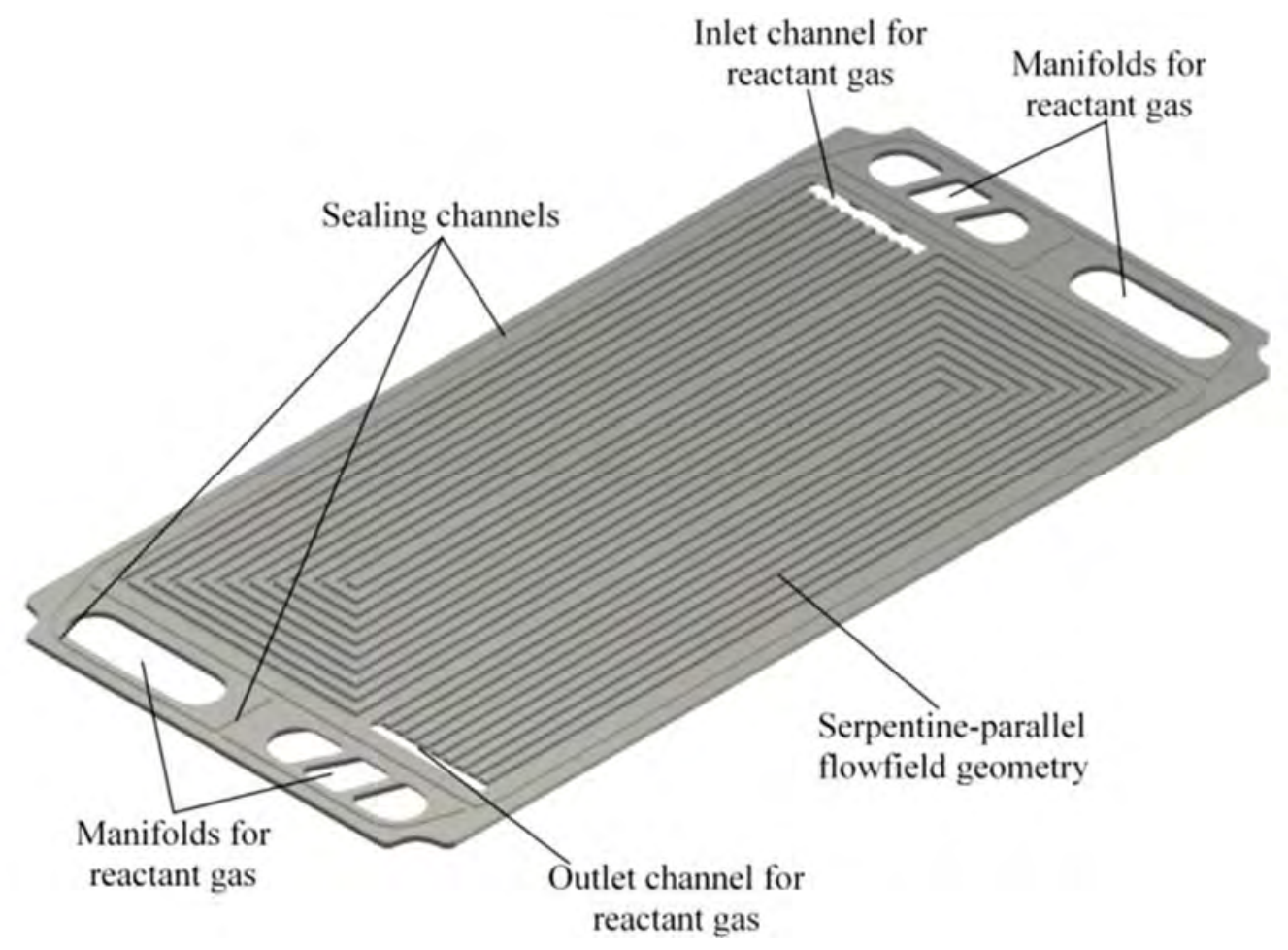

Figure 1. Sketch of the channels side of monopolar plates

To reduce as much as possible the stack weight it was decided to manufacture monopolar plates in very thin sheets of 5083 aluminum. In the case of cathode plates the final thickness is $2 \mathrm{~mm}$, while for the anode ones it is reduced to only $1 \mathrm{~mm}$. As it is well known, metallic plates used as bipolar or monopolar plates in PEMFCs are normally protected from corrosion caused by the acid media applying different surface coatings [1721]. In the present research, a $40 \mu \mathrm{m}$ thick thin layer of $\mathrm{Ni}-\mathrm{P}(10-12 \% \mathrm{P})$ was deposited over the whole surface using electroless techniques to improve its corrosion resistance [22]. So, the resulting mass of the surface coated anode plates is only $23 \mathrm{~g}$, and $42 \mathrm{~g}$ for the cathode ones. 


\subsection{Reactant gases feeding system}

Using a similar procedure to that described to design the flowfield geometry, the size of the main manifolds (inlet and outlet) for the circulation of the reactant gases was designed, considering that the pressure drop to the gas flow imposed by the flowfield geometries must be at least 10 times larger than that in the manifolds [23,24]. With the calculated nominal flow of reactant gases, a rectangular cross section $27 \times 8 \mathrm{~mm}^{2}$ has been selected for the manifolds. So, for the nominal flow of hydrogen and oxygen the resulting pressure ratios $\Delta \mathrm{P}_{\text {flowfield }} / \Delta \mathrm{P}_{\text {manifold }}$ are 222.8 and 76.5 , respectively.

Following the excellent results obtained in previous studies, hydrogen and oxygen are supplied to the flowfield geometries from the back side of the plates [25]. To this end, a lowered step has been manufactured in the back side that communicates the main gas manifolds with a thin slit that connects to the inlet section of the channels of the flowfield on the front side. Access of reactant gases to the reaction zones is simplified with this design, together with the assembly of the different cells of the stack. It should also be noted that, in order to improve mechanical resistance of these zones, two ribs are also machined, as can be observed in Fig. 2.

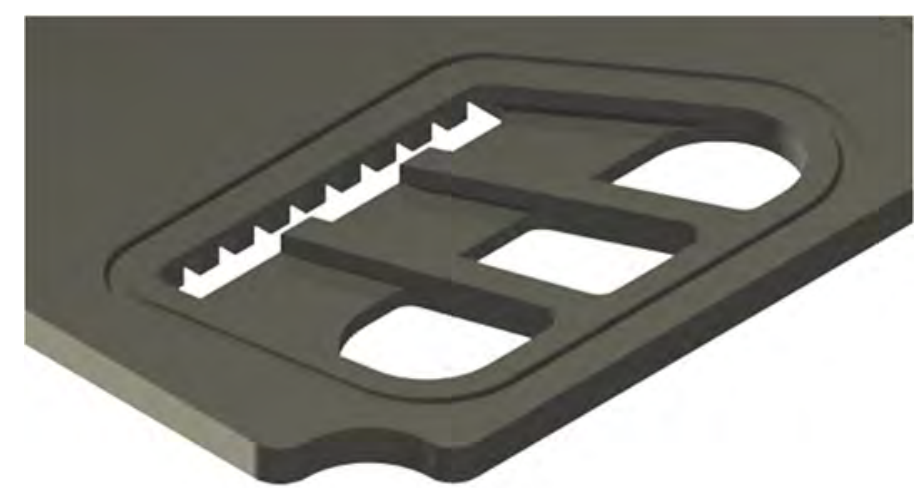

Figure 2. Lowered step machined in the back side of the plates to supply reactant gases to the flowfield geometry

\subsection{Sealing and closing systems}

To avoid gas leaks, in particular of hydrogen, a rectangular channel $1 \mathrm{~mm}$ wide and 0.5 $\mathrm{mm}$ deep has been machined surrounding each gas manifold and the flowfield geometry (see Fig. 1) in the front side of the plates, and also surrounding the ducts for gas manifolds in the back side (see Fig. 2). A cord of Loctite ${ }^{\circledR} 5910$ that supports the working temperature (above $200^{\circ} \mathrm{C}$ ) was automatically deposited into the sealing channels using a 3-D Cartesian desktop I\&J Fisnar 2500N dispensing robot. Once cured at room temperature, the resulting diameter of the flexible gasket was $1.2 \mathrm{~mm}$, which was controlled by 
regulating the injection pressure, the diameter of the deposition needle, and the selected displacement speed.

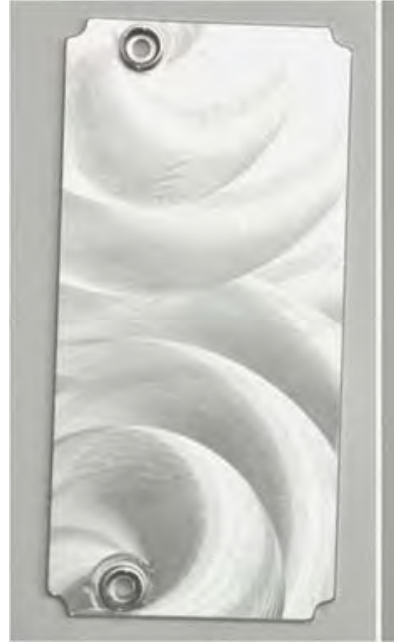

a)

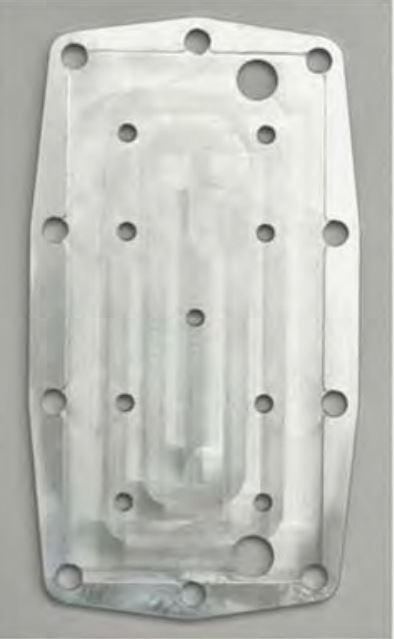

b)

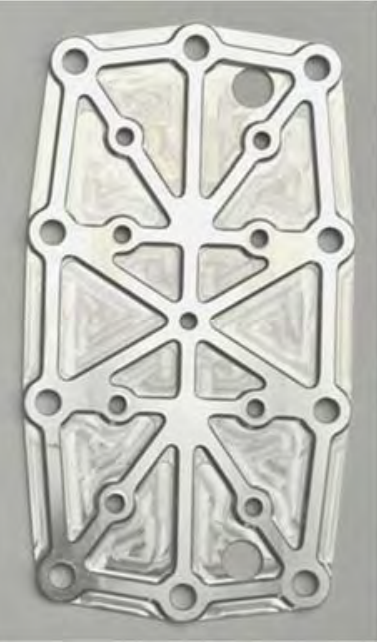

c)

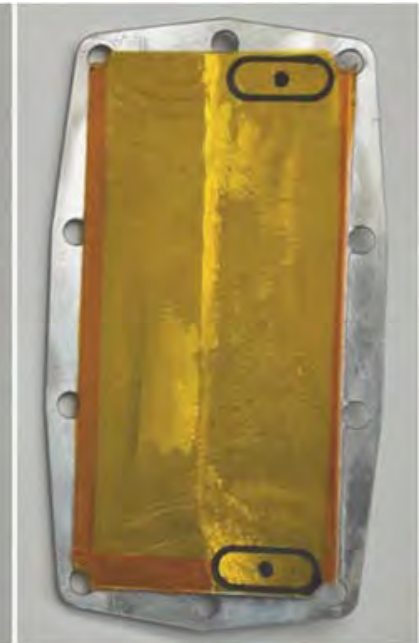

d)

Figure 3. Different photos of pressure-transmitter and endplates used in the stack.

Some other elements are needed to effectively close the stack, namely pressuretransmitter plates and endplates. Photos of the two sides of both plates can be observed in Fig 3. Endplates have 10 passing-holes for M6 screws located on its periphery, as well as 9 threaded-holes also for M6 screws distributed in the central area as depicted in Figs. 3b) and 3c). With this strategy a uniform force can be exerted over the whole active area of MEAs, simultaneously preventing the sagging of these plates, and reducing the total force needed to close the stack. To reduce the weight, endplates are manufactured in aluminum 5083 with a thickness of $5 \mathrm{~mm}$. The external side (Fig. $3 \mathrm{c}$ ) is designed in such a way that most of the material can be removed when machined still ensuring the mechanical resistance needed for these elements. Pressure-transmitter plates are also manufactured in aluminum $50835 \mathrm{~mm}$ thick. Two ports are machined to connect the reactant gases as displayed in Fig. 3a). They are placed between the endplates and the electrical collector ones, in such a way that the pressure of the central screws is exerted over these elements instead of over the current collector. To electrically isolate these elements from the rest of the cell, one side is covered by a film of Kapton ${ }^{\circledR} 0.5 \mathrm{~mm}$ thick, as shown in Fig. 3d).

\subsection{Assembling and formation of the stack}

A feature of Celtec-P MEAs is that they are highly hygroscopic. So, if they are exposed to humid air at room temperature, water is absorbed and the diluted phosphoric acid may 
tend to partially wash out and to migrate towards the plate channels. In the same way, contact to liquid water must be avoided, because it would slowly leach out of the electrolyte [26]. For this reason, they are vacuum packed in factory inside individual metallic vapor barrier bags. In order to achieve the very low humidity environment required by these MEAs, the assembly zone was isolated from the rest of the room by using a commercial plastic greenhouse [25]. To decrease the relative humidity inside the greenhouse, two pipes connected to the main air pressure line were strategically placed just over the assembly table and the hydraulic press.

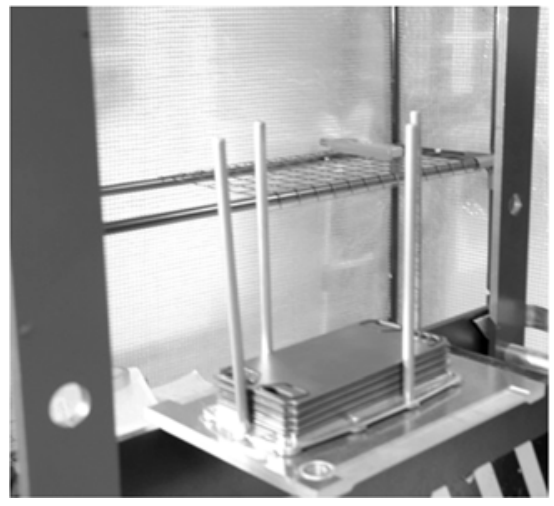

a)

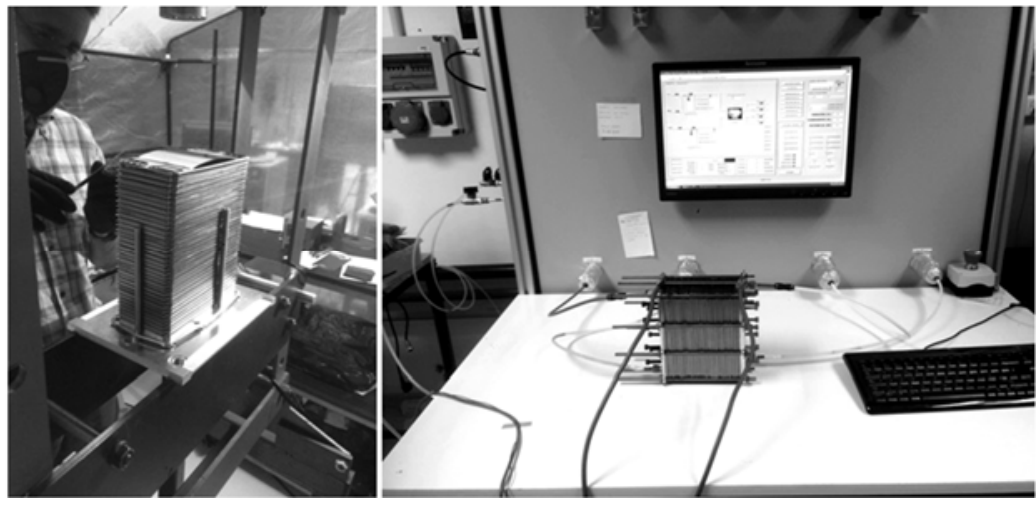

b)

c)

Figure 4. Photos showing different stages of the assembling procedure of the stack inside the greenhouse (a) and b), as well as the stack closed (c) ready to start the conditioning procedure at the test bench.

Once all sealing cords are deposited on the corresponding channels and they are properly cured, the assembling procedure can start. To form the stack, a special assembling plate with 4 centering rods and orifices to host gas connectors and 6 of the external screws is used, as shown in Fig. 4a). It is placed on the base plate of a hydraulic press, and one of the endplates is placed over it followed by the corresponding pressuretransmitter and current collector plates. Then, the first anode monopolar plate is assembled, with the plane side in direct contact with the current collector plate. Afterwards, a MEA is placed over the reaction zone formed by the channels of the flowfield geometry, and the reaction side of one of the cathode plates is placed over the other side of the MEA forming the first cell. The other 39 cells are assembled in a similar way (see Fig. 4 b), as well as the other current collector and pressure-transmitter plates. Subsequently, the other endplate is placed, and the $6 \mathrm{M} 6$ external screws that match the orifices of the assembling plate are placed and screwed by hand. After that, the 4 centering rods are unscrewed from the assembling plate and the remaining 4 M6 screws are bolted. Once 
all nuts are screwed, a force of 20 bar is applied with the hydraulic press, and the tighten process starts following a "cross-scheme" applying a final closing torque of $1.5 \mathrm{~N}-\mathrm{m}$ with a calibrated torque wrench. The total length of the stack was set to $152 \mathrm{~mm}$, while the actual weight was only $3.65 \mathrm{~kg}$.

Finally, the closing force for the 9 M6 screws placed on the central zone of the endplates is optimized using electrochemical impedance spectroscopy, and simultaneously checking that all plates are completely flat. For this purpose, an Autolab/PGSTAT302 with a frequency analyzer module FRA2 was used, applying a current of $1 \mathrm{~A}$ and a voltage of $10 \mathrm{~V}$ through the collector plates of the block. It was verified that the overall Ohmic resistance of the stack drastically decreased when the closing force increased from 0 to $2 \mathrm{~N}-\mathrm{m}$, demonstrating the importance of the central screws. A photo of the HT-PEMFC stack ready to be tested is shown in Fig. 4c).

\section{Design of the cooling system}

Once the HT-PEMFC stack is working under a stationary regime, the cooling system has to be capable of granting a stable temperature in the range between $140^{\circ} \mathrm{C}$ and $180^{\circ} \mathrm{C}$. To this end, it is necessary to calculate the amount of coolant needed. In the configuration considered for this application, the stack will be placed into a thermally-insulated reservoir (like a Dewar flask) located inside the fuselage of the UAV. So, the crosssectional area where the coolant will flow is the one corresponding to the annular space between the HT-PEMFC stack and the inner wall of the thermally-insulated reservoir.

\subsection{The 1D numerical model}

To perform the optimal design for the air-cooled system of the HT-PEMFC, a 1D theoretical model has been developed as a predictive tool with reduced requirements of computational resources $[27,28]$. It is formed by three submodels: one to characterize the electrochemical performance of the stack, another one related to mass transfer phenomena, and the thermal model itself. Some initial hypotheses have been taken into account. On the one hand, it has been considered that the stack will operate at $160^{\circ} \mathrm{C}$ under stationary conditions. For this temperature $\left(>100^{\circ} \mathrm{C}\right)$, the species considered at the inlet are only dry reactant gases $\left(\mathrm{H}_{2}\right.$ and $\left.\mathrm{O}_{2}\right)$. At the outlet, water generated in vapor phase is also considered, in addition to the exhaust reactant gases. On the second hand, the coolant considered is atmospheric air. Finally, a third assumption is that the only heat transfer mechanisms considered are convection and radiation. This supposition implies that the 
conduction process is neglected, and the stack can be treated as a single body characterized by a single temperature. The validity of this hypothesis was demonstrated in a previous study for the range of Nusselt numbers of this application, because Biot number (Bi) ranges between 0.0007 and 0.004 [29]. When Biot number is below 0.01 temperature gradients inside the object can be definitively neglected because heat conduction is indeed much faster than the heat convected away from its surface [30].

Strictly speaking, the heat generated by the electrochemical reaction in the catalyst layers of a PEMFC has a reversible part and an irreversible one. Reversible heating, i.e. the Peltier effect, comes from the entropy change for the relevant half-cell reaction. Irreversible heating has two sources. The first one is the heat released due to the activation potential, and the second irreversible source arises in the form of Joule (or Ohmic) heating in both the electronic and ionic conducting elements [31]. Indeed, all these local heat fluxes are very relevant, and have to be considered when a detailed numerical simulation of the complex and coupled transport processes taking place inside a cell or a stack is performed. However, when the electrochemical device is analyzed as a whole (blackbox), the problem is simplified, and local heat fluxes can be included into an overall process that quantifies the energy dissipated from the stack to the surroundings. This is the strategy considered in the present study.

A fuel cell stack, as any energy generation system, must comply with the energy conservation principle that can be expressed as:

$$
\sum_{i}\left(\dot{m}_{i} H_{i, \text { inlet }}\right)-\sum_{i}\left(\dot{m}_{i} H_{i, \text { outlet }}\right)=W_{\text {elec }}+Q_{\text {dis }}
$$

in which $\dot{m}_{i}$ is the mass flow rate of element " $i$ " $(\mathrm{kg} / \mathrm{s}), H_{i, \text { inlet }}$ is the inlet entalpy of element " $i$ " $(\mathrm{J} / \mathrm{kg}), H_{i, \text { outlet }}$ is the outlet entalpy of element " $i$ " $(\mathrm{J} / \mathrm{kg}), W_{\text {elec }}$ is the electric power of the stack $(\mathrm{W})$, and $Q_{\text {dis }}$ is the heat released that must be equal to the heat extracted by the cooling system (W).

From an energy balance, heat dissipated from the stack $\left(Q_{d i s}\right)$ has to be equal to that absorbed by the air $\left(Q_{\text {air }}\right)$. This can be expressed as

$$
Q_{\text {dis }}=Q_{a i r}=\dot{m}_{a i r}\left(H_{a, o}-H_{a, i}\right)
$$

where $\dot{m}_{a i r}$ is the cooling air mass flow rate, while $H_{a, i}$ and $H_{a, o}$ are air inlet and outlet enthalpy respectively. As it was demonstrated, natural convection by itself is not capable to cool down the stack. The heat absorbed by the air is the sum of the convective and the radiative components

$$
Q_{H T}=Q_{c o n v}+Q_{\text {rad }}
$$

and heat transferred by radiation can be expressed as 


$$
Q_{\text {rad }}=\sigma \epsilon_{F C} F_{F C}\left(T_{w}^{4}-\bar{T}_{\text {air }}^{4}\right)
$$

Here $\sigma$ is the Stefan-Boltzmann constant, $\epsilon_{F C}$ the stack emissivity, $F_{F C}$ the heat transfer area of the stack, $T_{w}$ the stack surface temperature, and $\bar{T}_{\text {air }}$ the air temperature averaged between the cooling system inlet and outlet. Equation (4) includes the energy radiated by the stack, considered as a unique body, and the radiative energy that it absorbs. It assumes that the stack absorption coefficient is equal to its emissivity, according to Kirchhoff's law for a grey body.

Heat transferred by convection is defined by

$$
Q_{\text {conv }}=h F_{F C} \overline{\Delta T}_{\text {log }}
$$

where $h$ is the convective heat transfer coefficient, and $\overline{\Delta T}_{\text {log }}$ the mean logarithmic temperature difference that is calculated by

$$
\overline{\Delta T}_{l o g}=\frac{\left(T_{w}-T_{a, i}\right)-\left(T_{w}-T_{a, o}\right)}{\ln \left(\frac{T_{w}-T_{a, i}}{T_{w}-T_{a, o}}\right)}
$$

$T_{a, i}$ and $T_{a, o}$ are the air inlet and outlet temperature. The convective heat transfer coefficient, $h$, for the coolant flowing along an annular space surrounding a PEM fuel cell stack is usually estimated using the definition of the Nusselt number,

$$
\mathrm{Nu}=\frac{h \cdot D_{e q}}{\lambda_{\text {air }}}
$$

where $\lambda_{\text {air }}$ is the air thermal conductivity. In the present study, the characteristic length considered is the equivalent diameter of the cross-sectional area of the cooling fluid flow, $D_{e q}$, that is defined by

$$
D_{e q}=\frac{4 A_{f}}{P_{w e t}}=\frac{4\left(A_{\text {Cond }}-A_{F C}\right)}{P_{\text {cond }}+P_{F C}}
$$

in which $A$ and $P$ refer to area and perimeter, respectively. Subscripts " $f$ ", "wet", and "Cond" indicate flow, wetted (whether in contact or not with the heat transfer surface), and cooling conduct, respectively.

The Nusselt number, $\mathrm{Nu}$, can be calculated using two empirical models experimentally obtained in a previous research performed in two wind tunnels with a similar configuration as that of the UAV [29], namely:

$$
\mathrm{Nu}=0.6155 \operatorname{Re}^{(2 / 3)}\left(\frac{D_{e q}}{L}\right)^{(3 / 4)} \operatorname{Pr}^{(1 / 3)}
$$

for $\operatorname{Re}\left(\frac{D_{e q}}{L}\right) \geq 640$, and

$$
\mathrm{Nu}=0.002149 \operatorname{Re}^{(3 / 2)}\left(\frac{D_{e q}}{L}\right)^{(4 / 3)} \operatorname{Pr}^{(1 / 3)}
$$

for $\operatorname{Re}\left(\frac{D_{e q}}{L}\right) \leq 560$. 
The non-dimensional group $D_{e q} / L$ is known as the form factor, where $L$ is the length of the stack. Results obtained showed that the heat transfer coefficient varies from 8 to 44

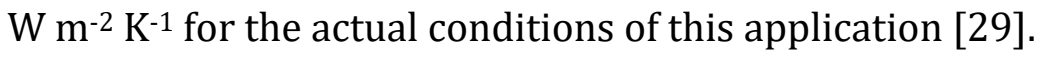

Finally, the heat balance is closed by minimizing the deviation error in eqs. (2) and (3) defined by,

$$
\Delta Q_{\text {error }}=100\left|\frac{Q_{H T}-Q_{\text {dis }}}{Q_{\text {dis }}}\right| .
$$

To perform the numerical simulations, the model has been implemented using the "Engineering Equation Solver" (EES) commercial software. To obtain the numerical solution a golden section search method has been used with a relative convergence tolerance of $10^{-9}$.

\subsection{Optimization of the coolant flow cross-section}

For the calculated air flow, the total flow area has to be optimized for the configuration considered in the present study. Variations in the cooling flow section are influential on the heat transfer, because both the equivalent diameter and the convective heat transfer coefficient can be modified. The required cooling flow rate, taking into account pressure losses that also depend on the flow cross-sectional area, determines the power required to circulate the flow along the cooling circuit:

$$
\dot{W}=\Delta p_{f} V A_{f}
$$

in which $V$ is the air velocity. Pressure losses $\Delta p_{f}$ can be evaluated according to

$$
\Delta p_{f}=\rho K \frac{V^{2}}{2}
$$

Here, friction losses have been neglected compared to those due to sudden changes in flow section and direction. Constant $K$ includes both minor losses in the cooling system, $K_{\text {cool, }}$ and the losses due to valves, $K_{v a l v}$, used to regulate the amount of air flow circulating around the stacks, and can be written as

$$
K=K_{\text {cool }}+K_{\text {valv }}
$$

The coefficient of minor losses in the cooling system, $K_{\text {cool }}$, can be considered to be a function of the ratio between the cooling duct section and the flow section around the stack

$$
K_{\text {cool }}=10.73\left(1-\frac{A_{f}}{A_{\text {Cond }}}\right) .
$$

where the constant value 10.73 was experimentally obtained in [29]. Finally, to estimate $K_{\text {valv }}$ the air inlet pressure is calculated using Bernoulli equation by

$$
p_{a, i}=\frac{1}{2} \rho_{a i r}\left(V_{U A V}^{2}-V_{a, i}^{2}\right)
$$


where $\rho_{\text {air }}$ is the air density at the flying altitude, $V_{U A V}$ is the velocity of the aircraft at the flying altitude, and $V_{a, i}$ is the air inlet velocity. Adding these equations to the EES numerical code, the power consumption of the cooling system can be obtained.

\section{Results}

All the HT-PEMFC stack tests were performed in the dual test bench available at LIFTEC research facilities. After flowing dry $\mathrm{N}_{2}$ to verify that there were no leaks of reactant gases neither out of the device nor between cathodes and anodes, the following conditioning procedure was followed. This procedure is mandatory before starting the performance tests in order to ensure the proper operation of the device. In short, the stack is heated up to $120^{\circ} \mathrm{C}$ using a $5 \mathrm{~kW}$ industrial air heater. After that, small flows of $\mathrm{H}_{2}$ and $\mathrm{O}_{2}$ are supplied to anode and cathode sides in order to remove the remaining $\mathrm{N}_{2}$, and to fill the channels of the flow geometry with reactant gases. Once the device is ready, a low voltage is fixed in the electronic load, so that the current generated by the device increases gradually. When the current exceeds $20.3 \mathrm{~A}\left(0.25 \mathrm{~A} \mathrm{~cm}^{-2}\right)$, the electronic load working mode is changed to demand a constant current of $16.2 \mathrm{~A}$, which corresponds to a current density of $0.2 \mathrm{~A} \mathrm{~cm}^{-2}$ for this MEA. Under this condition, a gradual increase in voltage is detected, until the value of $16 \mathrm{~V}(0.4 \mathrm{~V} /$ cell $)$ is exceeded. Finally, a constant voltage of $16 \mathrm{~V}$ is demanded to the stack, and it is kept at this point for 8-10 hours, verifying that the electrical performance remains in steady state. The automatic gas supply unit of the test bench is regulated by software, ensuring that the stoichiometry of both hydrogen and oxygen flows is adjusted to 1.45 and 9, respectively for any value of current demanded by the electronic load as recommended by the MEA manufacturer.

\subsection{Electrical performance of the HT-PEMFC stack}

After the conditioning procedure, the stack is ready to be subjected to different charge demands, in order to determine polarization curves (V vs. I). To enlarge the lifetime of the stack it is important to note that it should never be operated at open circuit voltage. For this reason, a small current of $0.81 \mathrm{~A}\left(0.01 \mathrm{~A} \mathrm{~cm}^{-2}\right)$ must be drawn at the initial stage, to avoid the fast degradation of the cathode electrodes when exposed to high temperature and high potential conditions. It is also important that the demanded current is not increased until steady state conditions are verified for every working point. 


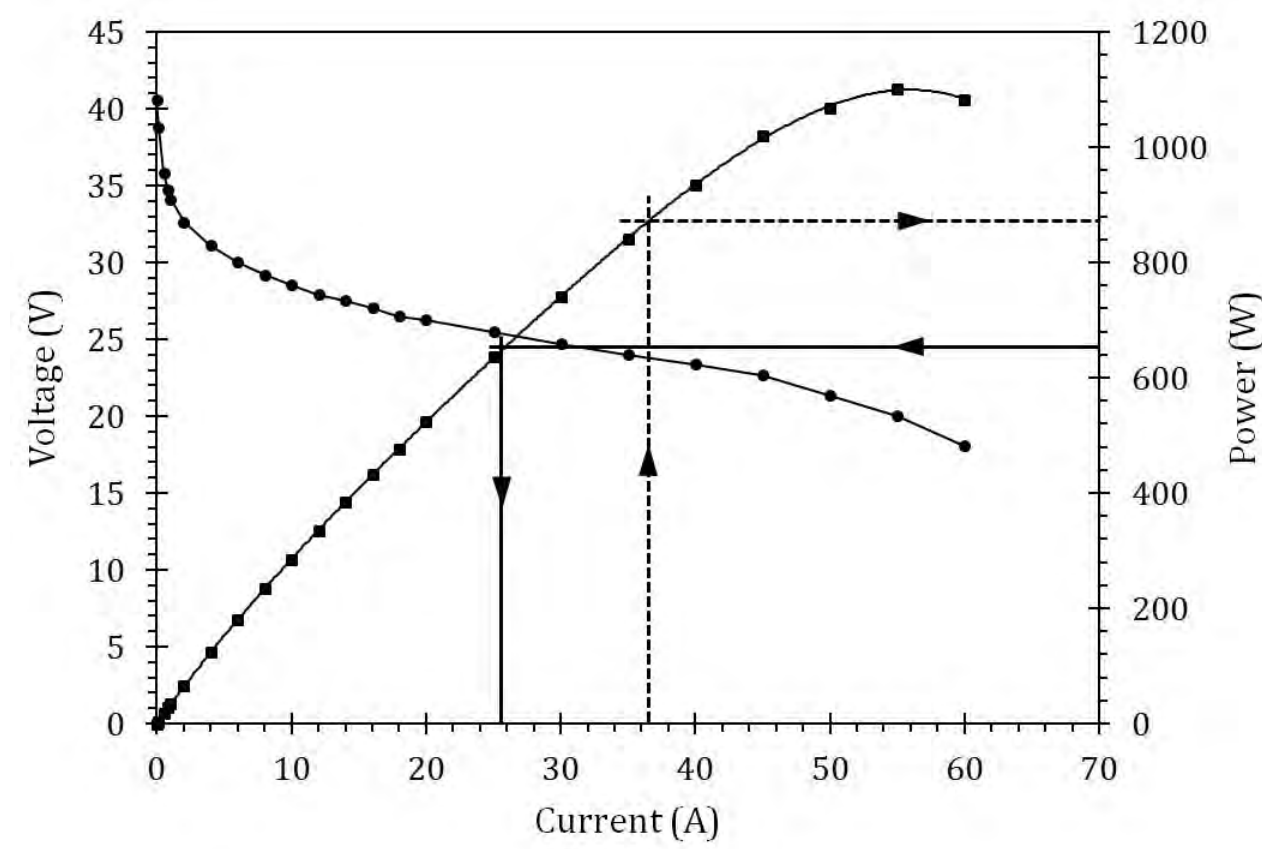

Figure 5. Polarization curve of the HT-PEMFC stack with the operational point during the ascending flight

One of the polarization curves obtained for the stack is depicted in Fig. 5. As can be observed, the zone corresponding to mass transfer losses common in low-temperature PEMFCs is not clearly visible, even after reaching current densities above $0.75 \mathrm{~A} \mathrm{~cm}^{-2}$. This behavior is typical of HT-PEMFCs because water remains in vapor phase, easing its management, and reducing the blockage of the small GDL pores in the cathode sides. For the operational point corresponding to a current density of $0.45 \mathrm{~A} \mathrm{~cm}^{-2}$ as recommended by the MEA manufacturer (36.6 A), dotted lines in Fig. 5, the power delivered by the stack is around $870 \mathrm{~W}$. This value is $35.4 \%$ higher than the power that should be supplied by the HT-PEMFC powerplant to the propeller $(650 \mathrm{~W})$ when ascending at a constant power [9]. So, for this operational point, which corresponds to the solid lines in Fig. 5 , the stack will work at a nominal current of $25.7 \mathrm{~A}\left(0.32 \mathrm{~A} \mathrm{~cm}^{-2}\right)$, enlarging the lifetime of the device. Besides, the maximum power delivered by the HT-PEMFC stack goes up to $1.1 \mathrm{~kW}$. This "excess of power" could be used to overcome harsh flying conditions, such as strong head or lateral wind, when needed, or by the air cooling system.

With these results, the nominal specific power of the stack is about $178 \mathrm{~W} \mathrm{~kg}^{-1}$ that goes up to $301.4 \mathrm{~W} \mathrm{~kg}^{-1}$ for the maximum power, which is in the range of Li-ion batteries [32]. For the test flights in the existing UAV it is planned to use a L45X composite cylinder from Luxfer Co. This bottle has a water capacity of $4.7 \mathrm{l}$ and can be filled with 74.65 g of $\mathrm{H}_{2}$ when compressed at 200 bar, resulting in $2.5 \mathrm{kWh}$ of energy stored. The con- 
sumption of hydrogen measured in the performance tests at the nominal power for a stoichiometry of 1.05 was around $40.56 \mathrm{~g} \mathrm{~h}^{-1}$ (8.32 $\left.\mathrm{Nl} \mathrm{min}^{-1}\right)$, what means that the flight range will be close to 1.85 hours. Considering that the total weight of the HT-PEMFC fuel cell-based powertrain (including the HT-PEMFC stack, electric motor, control electronic, pipes, valves, and reactant gases bottles) is of $9.35 \mathrm{~kg}$, the resulting specific energy is 267.4 Wh kg-1, again similar to modern Li-ion rechargeable batteries.

There are some other points about the performance of the lightweight stack that should be discussed. In order to ensure the correct temperature during the start-up, an external heating source (for example, a commercial air heater) must be considered. It should remain working when the current demanded to the stack is low. On the contrary, once the current demanded to the stack exceeds $13.5 \mathrm{~A}\left(0.165 \mathrm{~A} \mathrm{~cm}^{-2}\right)$ the heat produced by the electrochemical reactions is large enough to heat the stack up to $160^{\circ} \mathrm{C}$, and the external heat source can be disconnected. When the current demanded to the stack in steady state operation exceeds $15 \mathrm{~A}$, the heat yielded causes an abrupt temperature increase, and the air cooling system has to be activated to cool down the stack. For every working condition, the amount of coolant has to be regulated in order to maintain the stack temperature close to the nominal working value $\left(160^{\circ} \mathrm{C}\right)$.

\subsection{Cooling system}

As discussed before, natural convection and radiation from the device is not enough to extract all the heat produced to keep the stack temperature around $160^{\circ} \mathrm{C}$. So, a forced convection system has to be implemented. The required cooling air flow rate, taking into account pressure losses, determines the power required to circulate the coolant air flow along the cooling circuit. Typically, axial fans have been used as "active" cooling systems because of their easy integration and low noise. They are normally placed on one side of the cooling channels, forcing the air to pass through them working in suction regimen $[27,28]$. The use of an active cooling system formed by axial fans implies an increase in the total weight of the powerplant, as well as the necessity of a large space, which is very limited in this application. Besides, in the same way that the use of small ICEs in high altitude missions is discarded, cooling systems formed by axial fans are not suitable for the present application due to the very low atmospheric pressure at $10 \mathrm{~km}$. So, one of the aims of this study is to assess the design of a "passive" cooling system with a low power consumption without using axial fans. Considering the set of equations (1-11), and adding the five equations (12-16) to the 1D heat transfer numerical code, the power 
required to circulate the flow through the cooling circuit can be obtained as a function of the form factor $\left(D_{e q} / L\right)$. As in this case the dimensions of the HT-PEMFC stack are fixed, variations in the form factor are only influenced by changes in the distance between the stack and the inner wall of the thermally-insulated reservoir where the stack will be placed. This distance is here identified as the air cooling thickness.

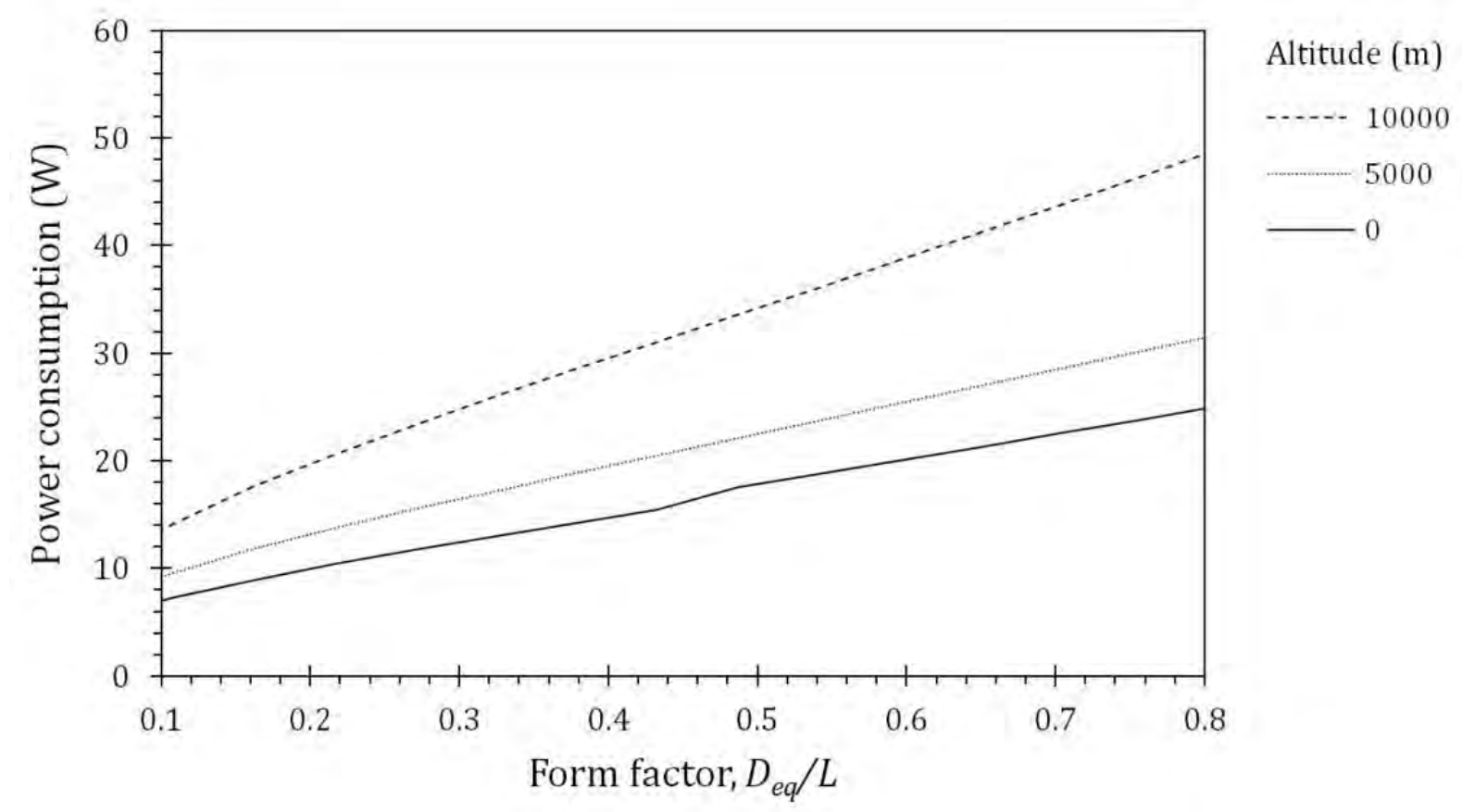

Figure 6. Behavior of the power consumption of the air cooling system as a function of the form factor at different flying altitudes.

Results depicted in Fig. 6 show the power consumption of the cooling system as a function of the form factor. In this case, the heat released power $(635.6 \mathrm{~W})$ is the one corresponding to the nominal operating point of the HT-PEMFC stack calculated by eq. (1). Air density and temperature variation with altitude are described by the formulas of a standard ISO atmosphere [33]. As can be observed in Fig. 6, the power consumption increases with increasing altitude and form factor. However, the air cooling thickness selected has to be compatible with the restriction imposed by the diameter of the fuselage. As the maximum fuselage diameter that can be considered for the existing UAV is limited to $250 \mathrm{~mm}$, the maximal air cooling thickness that can be achieved is only $30 \mathrm{~mm}$. To consider any value of air cooling system higher than $30 \mathrm{~mm}$ is unrealistic for this application. It was verified that, in the worse case when flying at the service ceiling $(10 \mathrm{~km})$ and for the largest possible form factor (0.3), which corresponds to an air cooling thickness of $28 \mathrm{~mm}$, a very low power below $25 \mathrm{~W}$ is consumed by the cooling system. 


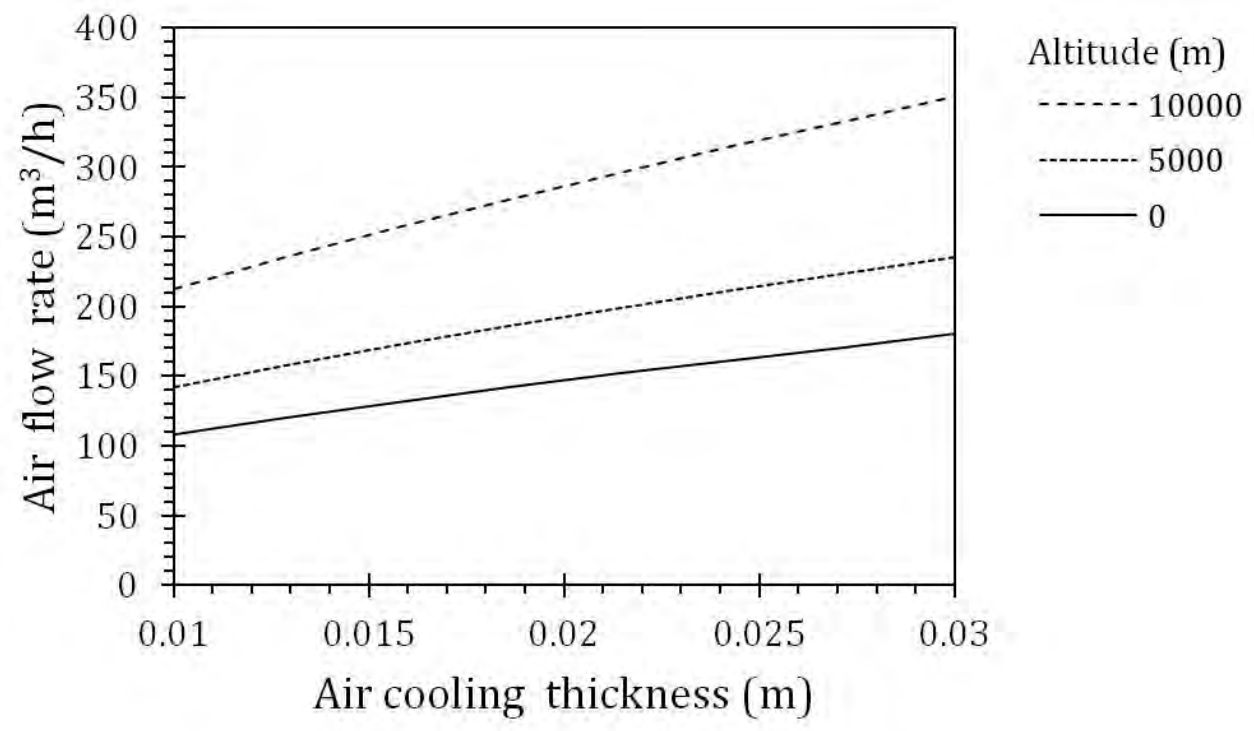

Figure 7. Behavior of the air flow rate needed to keep the stack temperature at $160^{\circ} \mathrm{C}$ as a function of the flying altitude and the air cooling thickness

Restricting the analysis to air cooling thicknesses ranging from 10 to $30 \mathrm{~mm}$, the behavior of the air flow rate needed to keep the stack temperature at $160^{\circ} \mathrm{C}$ as a function of the flying altitude and the air cooling thickness is depicted in Fig. 7. As can be observed, the higher the flying altitude the larger the air flow rate needed to cool the stack down. As it could be expected, the amount of coolant increases with increasing air cooling thickness. For the air cooling thickness of $30 \mathrm{~mm}$, it varies from $180 \mathrm{~m}^{3} \mathrm{~h}^{-1}$ at sea level to $350 \mathrm{~m}^{3} \mathrm{~h}^{-1}$ at $10 \mathrm{~km}$, while the variation is much smaller for the air cooling thickness of $10 \mathrm{~mm}$ (from $109 \mathrm{~m}^{3} \mathrm{~h}^{-1}$ to $190 \mathrm{~m}^{3} \mathrm{~h}^{-1}$ ). The value of air cooling thickness of $16 \mathrm{~mm}$ corresponds to the lowest form factor (0.175) tested in [29].

With these results, the corresponding velocity of the air flow surrounding the stack to keep the working temperature can also be estimated. As depicted in Fig. 8, the higher the flying altitude the higher the air velocity for any value of the air cooling thickness. However, an important result is that the velocity of the air needed to cool the stack down to $160^{\circ} \mathrm{C}$ is relative low even for the lowest cooling thickness $(10 \mathrm{~mm})$. A maximum air velocity of $11 \mathrm{~m} \mathrm{~s}^{-1}$ was obtained for this experimental condition. After evaluating the space available in the UAV, and considering also the results obtained in heat transfer numerical simulations, it was decided that the air cooling thickness selected for the thermally-insulated reservoir where the stack will be placed will be $16 \mathrm{~mm}$. 


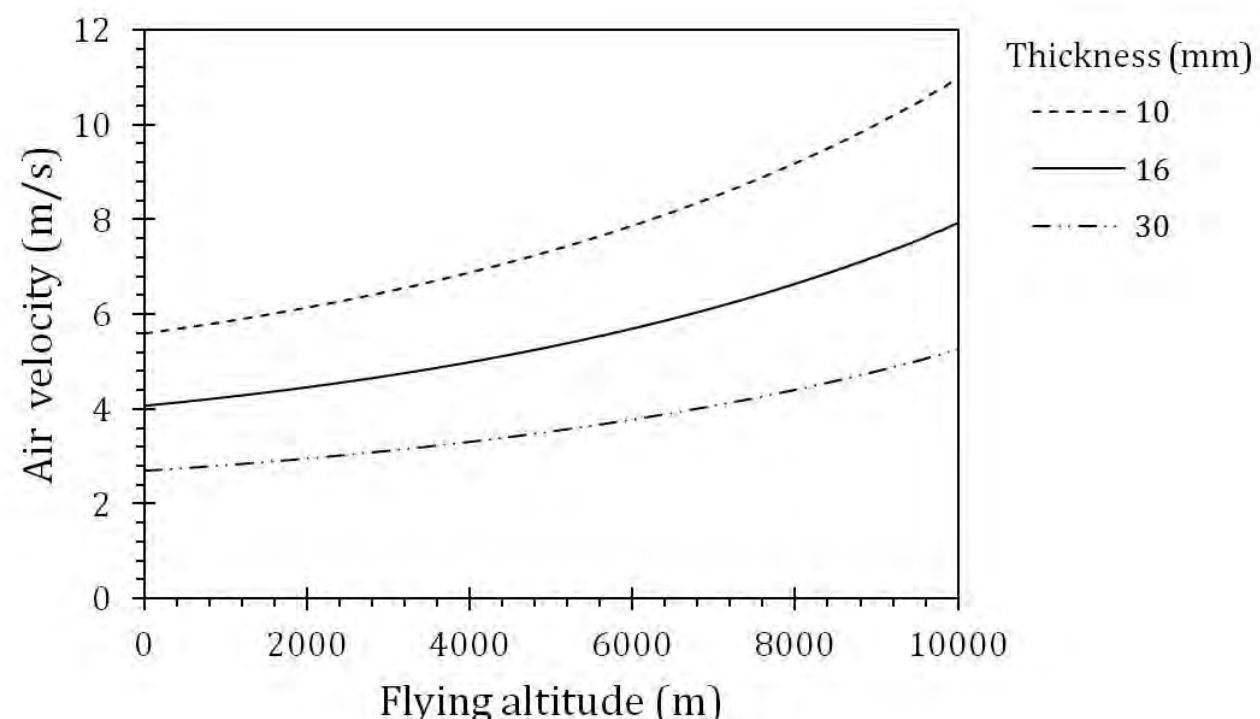

Figure 8. Air velocity as a function of the flying altitude for various air cooling thickness

Another important point that requires verification is the steady flow condition for the heat transfer problem where the stack is placed inside the fuselage and the resulting air cooling thickness is $16 \mathrm{~mm}$. The time dependence of the stack metal temperature can be expressed as a function of both Fourier $(F o)$ and Biot numbers (Bi) by the equation

$$
\frac{T-T_{\infty}}{T_{o}-T_{\infty}}=e^{-B i(F o)}
$$

in which $T$ is the temperature at time $t, T_{o}$ the temperature at time $t=0$, and $T_{\infty}$ the temperature at infinite time, and Fourier and Biot numbers are defined as,

$$
B i=\frac{h L_{c}}{\lambda_{b}} \text {, and } F o=\frac{\alpha t}{L^{2}}
$$

where $h$ is the convective heat transfer coefficient, $\lambda_{b}$ is the thermal conductivity of the body, $L c$ is the characteristic length defined as the volume of the body divided by its surface area $(V / A), \alpha$ is the thermal diffusivity, $t$ the characteristic time, and $L$ the length through which conduction occurs.

For the actual operating conditions it is obtained that the Fourier number ranges from 1.7 to 40 , and the temperature ratio $\left(\frac{T-T_{\infty}}{T_{o}-T_{\infty}}\right)$ varies from 0.852 to 0.999 . So, it is confirmed that for the range of air cooling flow rate needed to keep the stack temperature at $160^{\circ} \mathrm{C}$, the steady state is reached.

The temperature difference of the air flow between inlet and outlet for this air cooling thickness is depicted in Fig. 9 as a function of flying altitudes. As can be observed, it changes from $13.9 \mathrm{~K}$ at sea level to only $21.3 \mathrm{~K}$ at the service ceiling $(10 \mathrm{~km})$. It was also obtained that for this thickness, $16 \mathrm{~mm}$, the power consumption ranges from $9 \mathrm{~W}$ at sea level to less than $18 \mathrm{~W}$ at the service ceiling (see Fig. 6). This value represents an extra 
power lower than $2.75 \%$, which can be easily assumed by the HT-PEMFC stack.

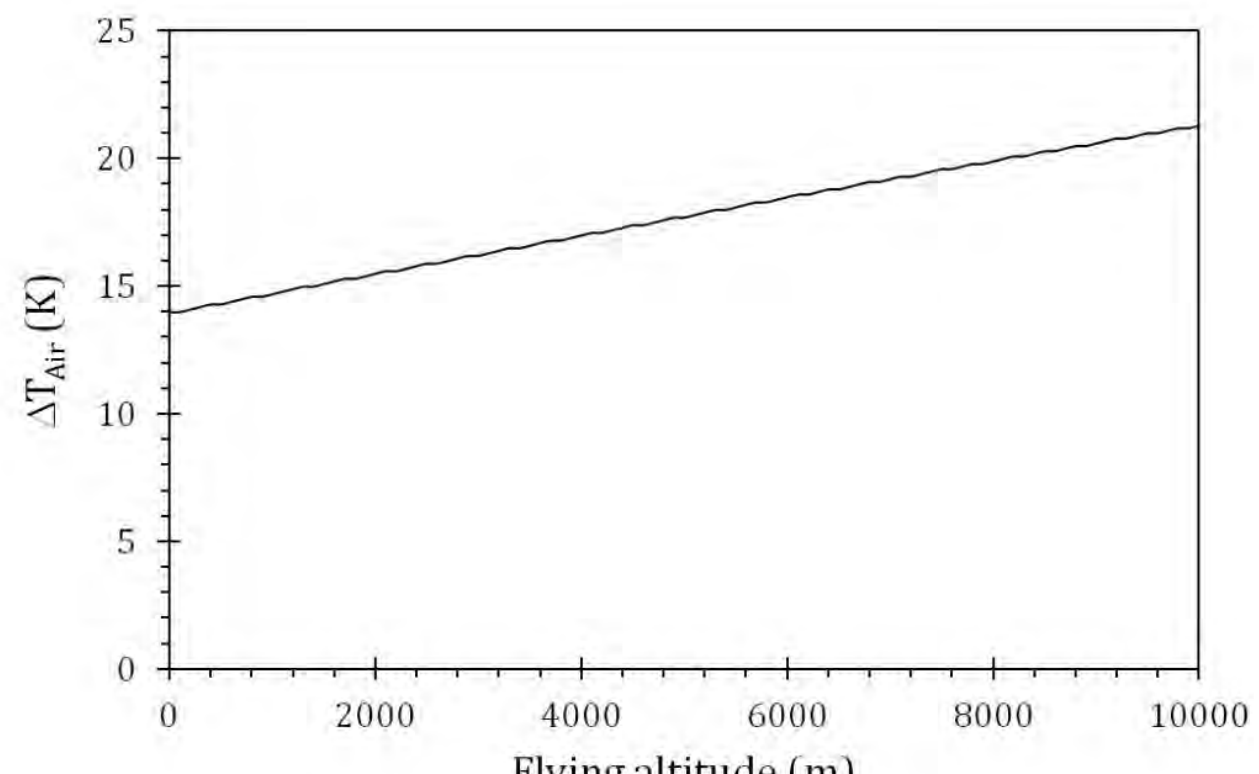

Figure 9. Temperature difference for the air cooling thickness of $16 \mathrm{~mm}$ as a function of the flying altitude

In Table 1, the velocity of the air cooling flow for the thickness of $16 \mathrm{~mm}$ for different flying altitudes is compared with the stall velocity of the UAV during the ascending flight. Considering that the UAV has to ascend at least at the stall velocity, the aircraft velocity at any flying altitude is always higher than that needed for cooling purposes. So, a passive cooling system can be used to cool the stack down to the working temperature $\left(160^{\circ} \mathrm{C}\right)$, employing the velocity induced by the UAV when flying.

\begin{tabular}{|c|c|c|c|c|c|c|}
\hline \multirow{2}{*}{$\begin{array}{c}\text { Velocity } \\
(\mathrm{m} / \mathrm{s})\end{array}$} & \multicolumn{7}{|c|}{ Flying altitude (m) } \\
\cline { 2 - 7 } & 0 & 2000 & 4000 & 6000 & 8000 & 10000 \\
\hline UAV (stall) & 20.56 & 22.68 & 25.15 & 28.02 & 31.41 & 35.43 \\
\hline Coolant & 4.06 & 4.45 & 4.98 & 5.70 & 6.65 & 7.95 \\
\hline
\end{tabular}

Table 1. Velocities of the UAV and the air cooling flow at different flying altitudes for the air cooling thickness of $16 \mathrm{~mm}$

A sketch of the passive cooling system considered is shown in Fig. 10. In this case, a new glass-fiber fuselage (A) with an inner diameter of $240 \mathrm{~mm}$ and $2 \mathrm{~mm}$ thick will be accordingly modified. The stack will be placed inside a glass-fiber reservoir with an internal rectangular cross-section of $(115 \times 203) \mathrm{mm}^{2}$ and a wall thickness of $2 \mathrm{~mm}$, similar to 
the small wind tunnel tested in [29]. The resulting "external" jacket (C) between the reservoir and the inner wall of the fuselage will be filled with insulating foam. The air will flow surrounding the stack into the reservoir by a circuit formed by two inlet ducts (D) with a diameter of $75 \mathrm{~mm}$ connected to the lateral of the fuselage, and an exit port (E) opened at the tail zone with a diameter of $107 \mathrm{~mm}$. With this decision the crossectional area of both inlet ducts and exit port is the same as that of the cooling area surrounding the stack, keping constant the air velocity for the maximum air flow. The system also includes movable valves placed at the inlet ducts (F) and a sliding cone (G) located at the exit ports. The opening area of the valves and sliding cone that regulates the amount of air flowing around the stack will be controlled by the measured stack temperature.

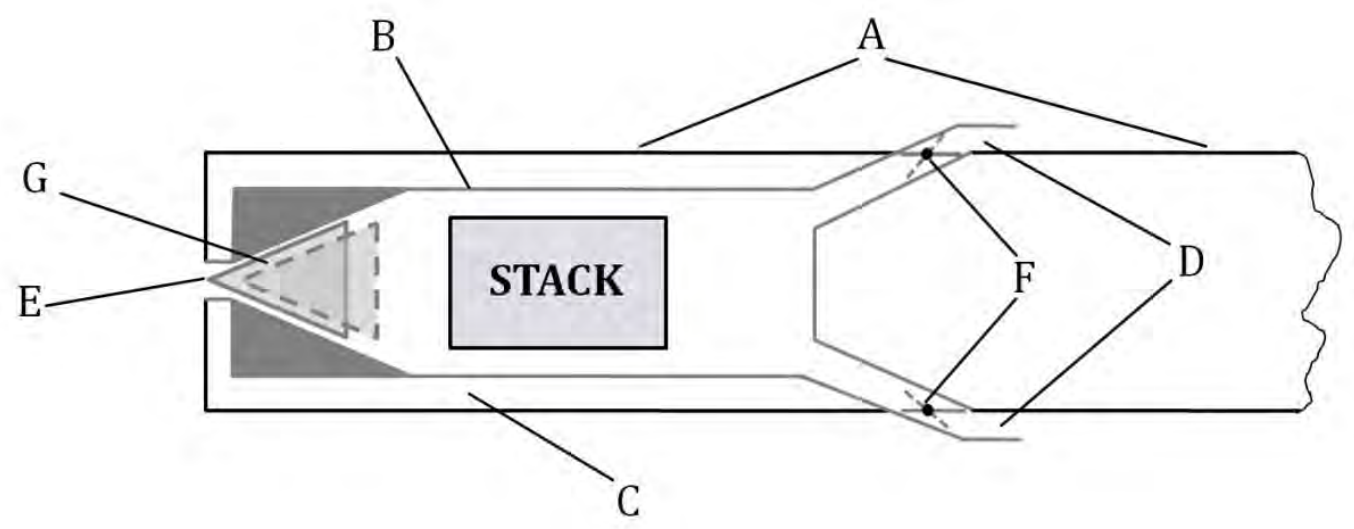

Figure 10. Scheme of the modified fuselage in order to include the stack and the passive air cooling system

\section{Conclusions}

The optimal design of a lightweight HT-PEMFC stack that will be used to power an UAV for a high altitude mission of $10 \mathrm{~km}$ has been performed. By using monopolar plates manufactured in very thin aluminum sheets the weight of the stack has been reduced to only $3.65 \mathrm{~kg}$. So, the maximum specific power of the stack is about $301.4 \mathrm{~W} \mathrm{~kg}^{-1}$, and the resulting specific energy of the HT-PEMFC fuel cell-based powertrain is $267.4 \mathrm{Wh} \mathrm{kg}^{-1}$, similar to modern Li-ion rechargeable batteries. Considering the consumption of hydrogen for the nominal operating point, the expected range of the flight will be around 2 hours using a L45X composite cylinder from Luxfer Co.

Simultaneously, a practical passive cooling system has been designed in order to maintain the stack temperature in the recommended value $\left(160^{\circ} \mathrm{C}\right)$ during the whole flight with minimum power consumption. This strategy implies that the stack will be cooled down discarding the use of compact axial fans, and complying with the stringent space 
and weight limitations imposed by this application. It is formed by a thermally-insulated reservoir where the stack will be placed, which is connected to the fuselage by two inlet ducts with movable valves, and a sliding cone placed at the exit port at the tail zone. The opening area of the valves and sliding cone that regulates the amount of air flowing around the stack will be controlled by the actual measured stack temperature. For the selected air cooling thickness $(16 \mathrm{~mm})$ a very low power consumption ranging from $9 \mathrm{~W}$ at sea level to less than $18 \mathrm{~W}$ at the service ceiling $(10 \mathrm{~km})$ has been calculated. This value represents an extra power for the HT-PEMFC stack less than $2.75 \%$.

\section{Acknowledgements}

This work has been partially funded by the Secretariat of State for Research of the Spanish Ministry of Economy and Competitiveness under project ENE2012-38642-C0201/CON. Support of the Regional Government of Aragon to the Experimental Fluid Dynamics Research Group (T03) is also acknowledged.

\section{References}

1. European Climate Foundation. Roadmap 2015: A practical guide to a prosperous, low carbon Europe-policy recommendations. (in http://www.roadmap2050.eu/)

2. International Energy Agency. World Energy Outlook 2009. Paris: OECD, International Energy Agency.

3. International Industry Working Group. Commercial aircraft design characteristics trends and growth projections, fifth ed., 2007.

4. Hydrogen, Energy and Fuel Cells - A vision for our future, High level group for hydrogen and fuel cells, Summary Report, 2003.

5. Fuel Cell Electric Vehicles: The Road Ahead, third ed. FuelCellToday, 2013. (in http://www.fuelcelltoday.com/).

6. T.H. Bradley, B.A. Moffitt, D.N. Mavris, D.E Parekh, Development and experimental characterization of a fuel cell powered aircraft. J Power Sources 2007; 171: 793-801.

7. T. Kim, S. Kwon, Design and development of a fuel cell-powered small unmanned aircraft. Int J Hydrogen Energy 2012; 37: 615-622.

8. T. Hauf, P. Shulte, R. Alheit, H. Schlager, Rapid vertical trace gas transport by an isolated midlatitude thunderstorm. J Geophys. Res. 1995; 100: 22,957-22,970. 
9. J. Renau, A. Lozano, J. Barroso, J. Miralles, J. Martín, F. Sánchez, F. Barreras, Use of fuel cell stacks to achieve high altitudes inlight unmanned aerial vehicles. Int J Hydrogen Energy DOI: 10.1016/j.ijhydene.2015.02.071.

10. J. Zang, Y. Tang, C. Song, J. Zang, Polybenzimidazole-membrane-based PEM fuel cell in the temperature range of $120-200^{\circ} \mathrm{C}$. J Power Sources 2007; 172: 163-171.

11. C. Wannek, I. Konradi, J. Mergel, W. Lehnert, Redistribution of phosphoric acid in membrane electrode assemblies for high-temperature polymer electrolyte fuel cells. Int J Hydrogen Energy 2009; 34: 9479-9485.

12. J. Lobato, P. Cañizares, M.A. Rodrigo, J.J. Linares, Pinar F.J., Study of the influence of the amount of PBI-H3PO4 in the catalytic layer of a high temperature PEMFC. Int J Hydrogen Energy 2010; 35: 1347-1355.

13. F. Barreras, A. Lozano, L. Valiño, C. Marin, A. Pascau, Flow distribution in a bipolar plate of a proton exchange membrane fuel cell: Experiments and numerical simulation studies. J Power Sources 2005; 144: 54-66.

14. A. Lozano, F. Barreras, L. Valiño, C. Marin, Imaging of gas flow through a porous medium from a fuel cell bipolar plate by laser-induced fluorescence. Exp in Fluids 2007; 42: 301-310.

15. F. Barreras, A. Lozano, L. Valiño, R. Mustata, C. Marin, Fluid dynamics performance of different bipolar plates. Part I. Velocity and pressure fields. J Power Sources 2008; 175: 841-850.

16. A. Lozano, L. Valiño, F. Barreras, R. Mustata, Fluid dynamics performance of different bipolar plates. Part II. Flow through the diffusion layer. J. Power Sources 2008; 179: 711-722.

17. A.M. López, F. Barreras, A. Lozano, L. González, J.A. García, L. Valiño, R. Mustata, Experimental study of the durability of two different coatings for aluminium-based bipolar plates used in PEM fuel cell stacks. J New Materials Electrochem Syst 2009; 12: 97-102.

18. J. Barranco, F. Barreras, A. Lozano, A. M. Lopez, V. Roda, J. Martin, M. Maza, G.G. Fuentes, E. Almandoz, $\mathrm{Cr}$ and $\mathrm{Zr} / \mathrm{Cr}$ nitride CAE-PVD coated aluminum bipolar plates for polymer electrolyte membrane fuel cells. Int J Hydrogen Energy 2010; 35: 11489-11498.

19. R.A. Antunes, M.C.L. Oliveira, G. Ett, V. Ett, Corrosion of metal bipolar plates for PEM fuel cells: A review. Int J Hydrogen Energy 2010; 35: 3632-3647. 
20. S. Karimi, N. Fraser, B. Roberts, F.R. Foulkes, A review of metallic bipolar plates for proton exchange membrane fuel cells: Materials and fabrication methods. Adv Mat Sci Eng 2012; 2012: art. nº. 828070.

21. R. Taherian, A review of composite and metallic bipolar plates in proton exchange membrane fuel cell: Materials, fabrication, and material selection. J Power Sources 2014; 265: 370-390.

22. See www.fagesbosch.com.

23. F. Barbir, Fuel cells: theory and practice, 1st ed. Burlington, MA: Elsevier Academic Press, 2005.

24. R. Mustata, L. Valiño, F. Barreras, M.I. Gil, A. Lozano, Study of the distribution of air flow in a proton exchange membrane fuel cell stack. J Power Sources 2009; 192: 185-189.

25. F. Barreras, A. Lozano, V. Roda, J. Barroso, J. Martín, Optimal design and operational tests of a high-temperature PEM fuel cell for a combined heat and power unit. Int J Hydrogen Energy 2014; 39: 5388-5398.

26. C. Henskel, Celtec ${ }^{\circledR}-\mathrm{P} 1000$ Membrane Electrode Assembly. Technical Information Brochure, D-BASF The Chemical Company, Frankfurt, 2011.

27. A.M. López-Sabirón, J. Barroso, V. Roda, J. Barranco, A. Lozano, F. Barreras, Design and development of the cooling system of a $2 \mathrm{~kW}$ nominal power open-cathode polymer electrolyte fuel cell stack. Int J Hydrogen Energy 2012; 37: 7289-7298.

28. F. Barreras, A. Lozano, J. Barroso, V. Roda, M. Maza, Theoretical model for the optimal design of air cooling systems of polymer electrolyte fuel cells. Application to a high-temperature PEMFC. Fuel Cells 2013; 13: 227-237.

29. J. Barroso, J. Renau, A. Lozano, J. Miralles, J. Martín, F. Sánchez, F. Barreras, Experimental determination of the heat transfer coefficient for the optimal design of the cooling system of a PEM fuel cell placed inside the fuselage of an UAV. Appl Therm Eng 2015; 89: 1-10.

30. D.F. Barbin, L.C. Neves Filho, V. Silveira Júnior, Convective heat transfer coefficients evaluation for a portable forced air tunnel. Appl Therm Eng 2010; 30: 229-233

31. A.A. Shah, K.H Luo, T.R. Ralf, F.C. Walsh, Recent trends and developments in polymer electrolyte membrane fuel cell modeling. Electrochimica Acta 2011; 56: 3731-3757

32. Panasonic overview information about Li-ion rechargeable batteries. (in http://na.industrial.panasonic.com/products/batteries/rechargeablebatteries/lithium-ion). 
33. Standard Atmosphere, ISO 2533:1975, Geneva, Switzerland, 1975. 